\title{
Analysis of the eigenfrequencies of the basalt machine parts by the FEM
}

\author{
Ilie Octavian Popp ${ }^{1 *}$ \\ ${ }^{1}$ Lucian Blaga University of Sibiu, Department of Industrial Machines and Equipment, 550025 \\ Victoriei 10, Sibiu, Romania
}

\begin{abstract}
The aim of this paper was to carry out a theoretical (numerical) scientific research on the behavior of cast and recrystallized basalt, in order to use it as a material in the manufacture of structural elements of machine tools. A unitary methodology has been established for studying the eigenfrequency of structural elements for machine tools by the finite element method. Two basalt structural elements (beam type and plate type) were modeled, which were also made physically, and with the help of the COSMOS / Mark finite element program, the eigenfrequencies of the models was studied.
\end{abstract}

\section{Introduction}

Basalt is an effusive volcanic rock composed of basic polyacids and ferromagnesian minerals. It is a very compact rock, dark gray or black, with a fine crystalline background in which the crystals have the shape of vertical prisms with a hexagonal section.

Mineralogically, basalt consists of a mixture of silicates with SiO4-type chemical bonds with a tetrahedral spatial configuration, very hard and resistant to chemical agents. The use of basalt products is justified, and it is necessary to look for other areas and methods where it would be possible to be used this material advantageously.

Although basalt is a material known to specialists in the silicate industry and in the field of construction, the same cannot be said about its use in the field of machine tool construction. The machine tool manufacturing industry has completely different characteristics from those found in construction and therefore extensive research is required to highlight the characteristics of basalt, exploit the advantages offered by it and eliminate the disadvantages [1], [2].

The rigidity performance of the machine tool structure as a whole is determined by the behavior of all components, the connections between them and the way in which stresses are transmitted between them. The elements with the greatest contribution to influencing the performance of the machine tool are the elements of the basic structure of the machine (frame, uprights, sleepers, supports, sleds, housings, etc.). Each of them must be properly designed to meet all the requirements of the precision of the machine tool [3], [4].

\footnotetext{
${ }^{*}$ Corresponding author: ilie.popp@ulbsibiu.ro
} 
Therefore, the problem of the behavior of basalt in specific loads, in order to be used in the manufacture of structural elements of machine tools, has not yet been addressed hence this paper aims to make a necessary introduction in this direction.

\section{General remarks}

The determination of the eigenfrequencies modes is the preliminary step prior to a dynamic analysis. This determines the natural state of the structure (the vector of time-varying loads $\{\mathrm{R}\}$ and the damping matrix $[\mathrm{C}]$ containing only zero elements) and the resonance at which the elastic deformations have the highest values.

The results of an eigenfrequency analysis can not provide the amplitude of physical vibration, but only the shape of the mode. For other results such as the true size of the deformation can be determined only if further information about excitation and damping properties are known. Determining the eigenfrequencies of a machine tool structure is part of structural engineering. One must take in consideration the following aspects: acknowledge that a resonance that may lead to excessive stresses is not caused by a periodic excitation, but the resonance may be in form of a piezoelectric vibrator; check if the analysis is suitable tacking in account that all natural frequencies are higher than the frequency of the loading. Further, this analysis provides eigenmodes for a subsequent analysis based on mode superposition and knowledge about how the design changes affect the eigenfrequencies by studying its mode shape.

\section{Modal analysis}

For the modeling of the eigenfrequency modes, elements such as beams and square plates were chosen, suspended by means of an elastic spring of negligible mass and required with impulse signal, structures similar to those used in the case of experimental research. These models have been used both to determine their own frequencies and modes of vibration and to determine the time-varying displacements, speeds and accelerations, depending on the mode of stress [5], [6].

Modeling the behavior of structures at dynamic stresses was performed using the COSMOS / M finite element program. The meshing of the models and the development of the calculation steps of the finite element analysis are performed by the computer program.

Initial conditions:

- geometry of the elements: beam $(\operatorname{axbxl}=40 \times 40 \times 250 \mathrm{~mm})$; plate $($ axbxh $=$ 300x300x40 mm);

- the material of the structures is cast basalt with elastic characteristics:

- dynamic longitudinal elastic modulus $\mathrm{E}=2.53104 \mathrm{~N} / \mathrm{mm} 2$ [3];

- depreciation factor or logarithmic decrease of depreciation $\delta=0.7710-2$;

When modeling the loading function, the pulse signal type function is used (Dirac's Ac function $\delta=\mathrm{f}(\mathrm{t}-\tau)$ ), and the simulation of the element support is done according to the initial free margin condition, in order to correspond to the tested experimental conditions (not presented in this paper).

In order to have sufficient information about the vibration modes of the structures, in the analysis performed, the first 10 eigenfrequencies were calculated and the eigenmodes corresponding to them were established. The subspace iteration method, which uses the generalized Jacobi algorithm, was used as the method to extract the eigenmodes. This method was preferred given the accuracy of the results it provides, as it works with whole stiffness and mass matrices. In this way, the user's choice of master's degrees of freedom was avoided. The normalization of the vibration modes was done in relation to the mass matrix. 
The values calculated for the ten modes of vibration are shown in Table 1. Figure 1 shows the initial state of the beam and plate type models with excitation and measurement points for the two models studied by FEM [7], in correspondence with the experimental tests performed (presented in [8]) and [9]). Figure 2 shows four of the deformations corresponding to the first 10 eigenmodes of the beam, respectively in figure 3 of the basalt plate, with the indication that the deformations of the average surface are represented.

Table 1. Values of the first 10 eigenfrequencies of basalt beam and plate models

\begin{tabular}{|l|l|l|l|l|l|l|l|l|l|l|l|}
\hline \multicolumn{2}{|l|}{ Frequencies } & $\mathbf{1}$ & $\mathbf{2}$ & $\mathbf{3}$ & $\mathbf{4}$ & $\mathbf{5}$ & $\mathbf{6}$ & $\mathbf{7}$ & $\mathbf{8}$ & $\mathbf{9}$ & $\mathbf{1 0}$ \\
\hline \multirow{2}{*}{$\mathrm{f}[\mathrm{Hz}]$} & beam & 238,6 & 556,1 & 2549 & 3910 & 4987 & 5120 & 8620 & 10336 & 12544 & 15564 \\
\cline { 2 - 12 } & plate & 260,8 & 1054 & 1938 & 2799 & 3611 & 3926 & 6352 & 6469 & 7195 & 7720 \\
\hline
\end{tabular}

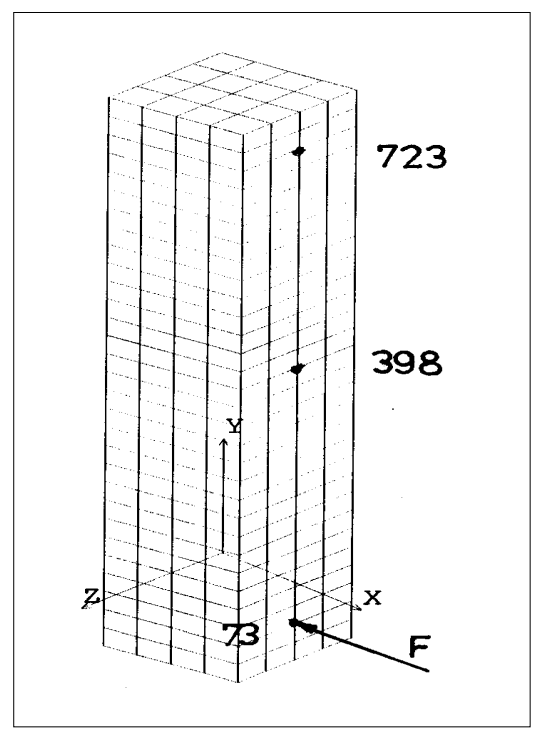

F_Mode $=0$

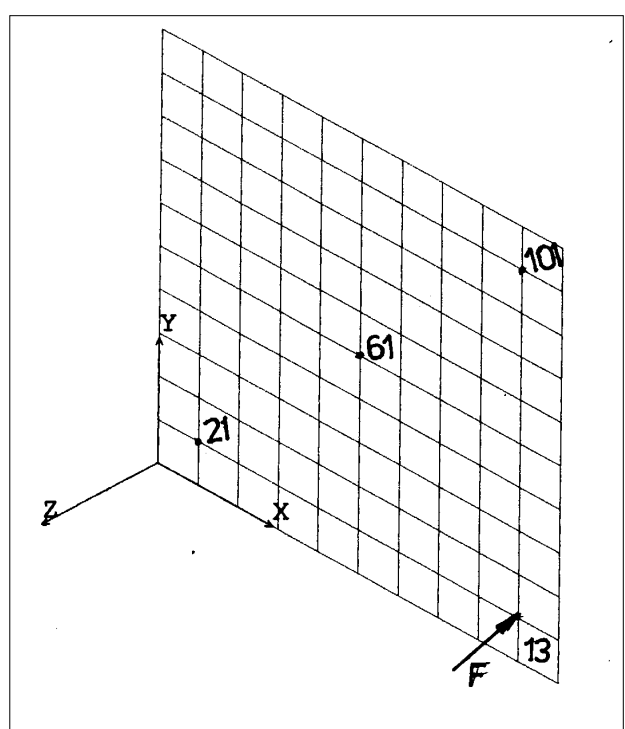

F_Mode $=0$

Fig. 1. Models of structures before requests

The first modes of vibration of the basalt beam model are decoupled, highlighting the trends of dynamic deformability of the structure, namely: bending in both main directions, twisting, axial and membrane deformations.

When researching the own frequencies, it is found that they are at a high level (239 $15564 \mathrm{~Hz}$ for the basalt beam and $260-7720 \mathrm{~Hz}$ for the basalt plate), thus these frequencies cannot be reached in practice, the field of work of the machine tools being located generally at low frequencies (generally below $50 \mathrm{~Hz}$ ). 


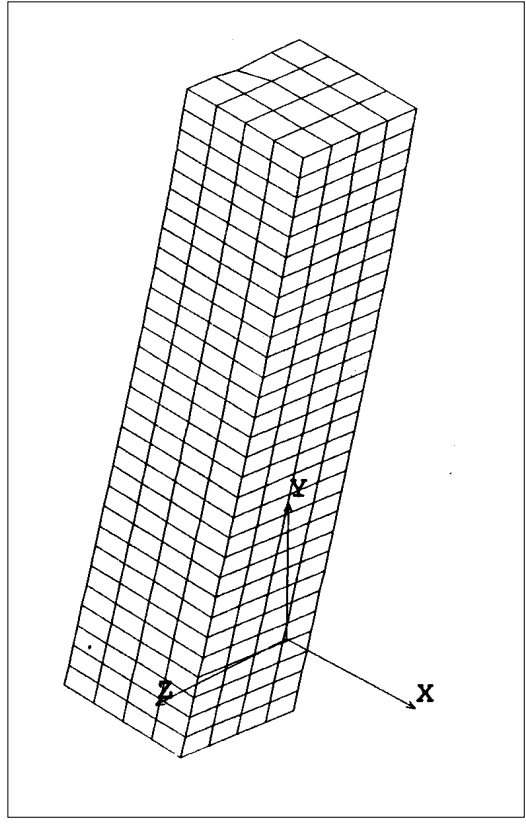

F_Mode $=2 \quad 556.057 \mathrm{~Hz}$

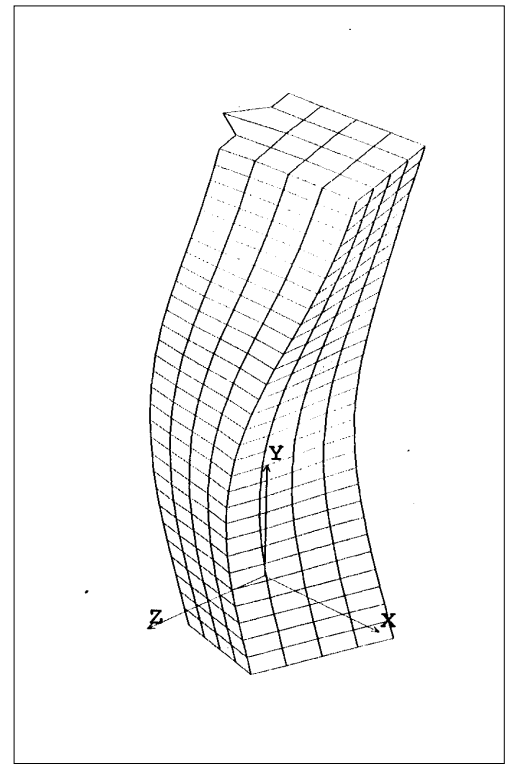

F_Mode $=7 \quad 8620.01 \mathrm{~Hz}$

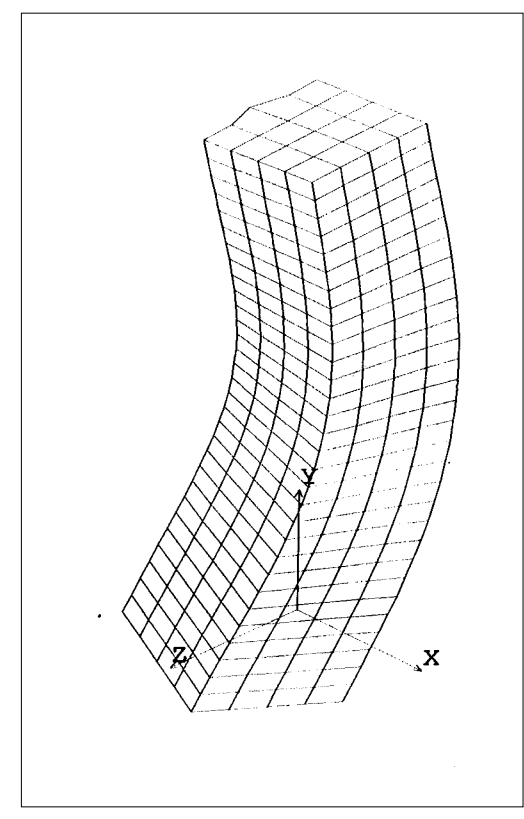

F_Mode $=5 \quad 4987.34 \mathrm{~Hz}$

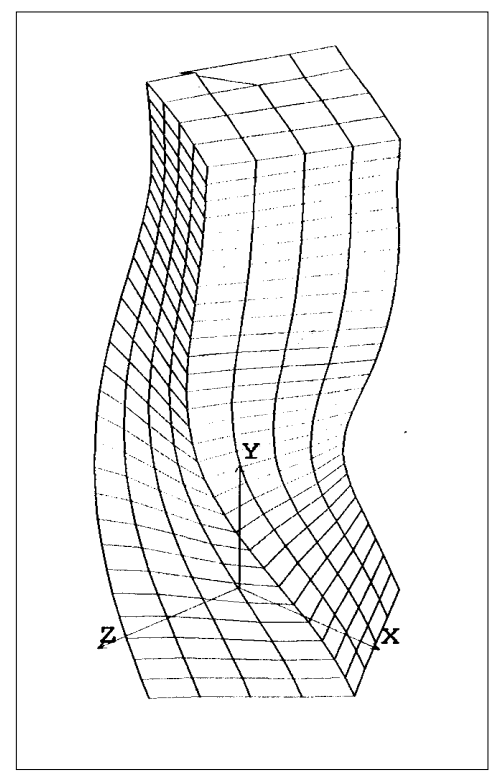

F_Mode $=9 \quad 12544.4 \mathrm{~Hz}$

Fig. 2 Own vibration modes for the basalt beam model 


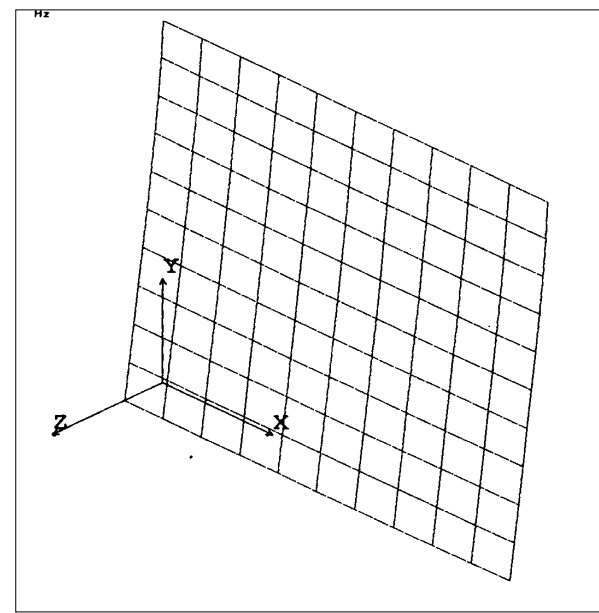

F_Mode $=1260.798 \mathrm{~Hz}$

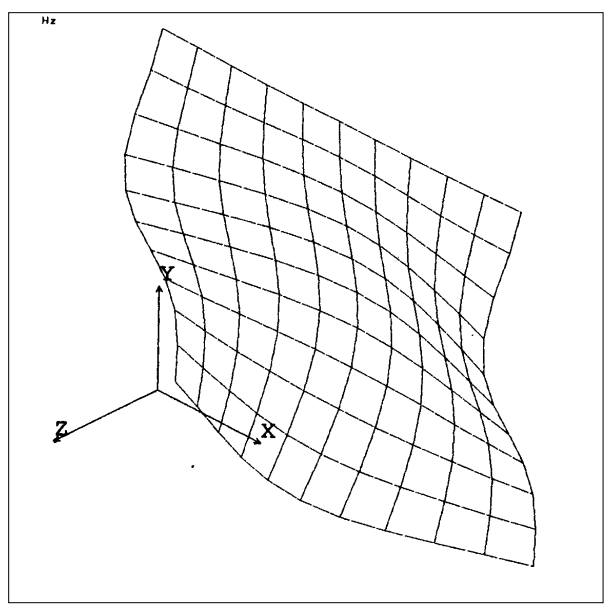

F_Mode $=7 \quad 6351.93 \mathrm{~Hz}$

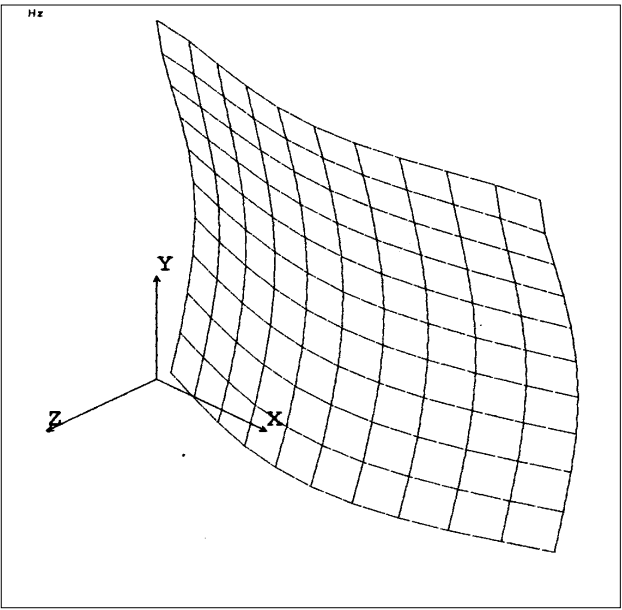

F_Mode $=4 \quad 2799.25 \mathrm{~Hz}$

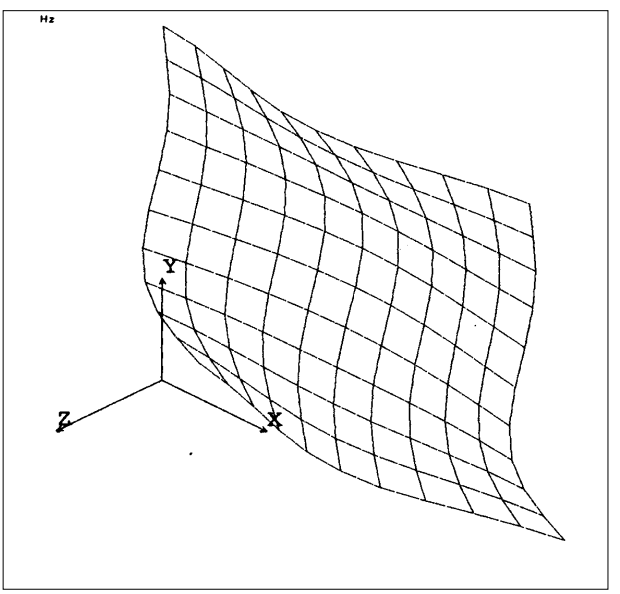

F_Mode $=9 \quad 7194.87 \mathrm{~Hz}$

Fig. 3 Own vibration modes for the basalt plate model

\section{Conclusions}

There are currently concerns about finding new resources for raw materials and materials to replace traditional ones. In this sense, the preoccupations of the author of this paper regarding the use of basalt as a construction material of the elements from the basic structure of machine tools are also included. Although basalt is a material known to specialists in the silicate and construction industries, it is not the same thing of its use in machine tool construction.

Regarding the use of basalt in the construction of the structural elements of machine tools, the property that recommends it the most is the wear resistance. Other aspects that recommend the use of this material in this domain are: large resources of cheap and easy to exploit raw materials; low energy consumption for obtaining it compared to the consumption 
for obtaining cast iron and steel; low specific gravity $\left(\rho=2.9 \mathrm{~g} / \mathrm{cm}^{3}\right.$ compared to cast iron with $\rho=7.8 \mathrm{~g} / \mathrm{cm}^{3}$ ).

The experimental methods of analysis are the most indicated in order to obtain precise results, but for this it is necessary to execute the structure to be analyzed and to have the necessary equipment for investigations. Following this analysis, the possibilities to eliminate possible inconveniences are limited. That is why it is necessary that the analysis of the behavior of the structure be done in parallel with its design.

From the point of view of the designer of the machine tool, it is important to know the first natural frequencies of the structural elements, because they should have higher values than its working frequencies, in order to avoid the resonance phenomena. In the modal analysis, with the help of the COSMOS / M program, the values of the first 10 eigenfrequencies were calculated.

Modeling and analysis by the finite element method demonstrates that basalt structures (beam elements and plates) can be better than similar ones, made of cast iron and steel, because their own vibrational frequencies do not enter the working frequency range of machine tools and therefore a possible resonance is excluded.

\section{References}

1. H.-C. Möhring, C. Brecher, E. Abele, J. Fleischer, F. Bleicher, CIRP Annals - Manufacturing Technology, 64, 725 - 748 (2015)

2. V. Ducatti, R. Lintz, J. Santos, International RILEM Conference on the Use of Recycled Materials in Building and Structures, Comparative Study with Alternative Materials for Manufacture of Machine Tool Structures, (Barcelona, Spain, 2004)

3. N. Kepczak, W. Pawlowski, Mechanics and Mechanical Engineering 17, 285-289 (2013)

4. T. Erbe, J. Król, R. Theska, ICPE, Mineral casting as material for machine base-frames of precision machines, (Portland, Oregon, 2008)

5. C. Ispas, C. Dogariu, C. Mohora, IMEC, Aspects of Behavior of Concrete in Machine Tool Structures using Finite Element Method (1993)

6. C. Ispas, C. Dogariu, I. Ghinea, AMTECH'93, Comparative Finite Analysis of Static, Thermic and Dynamic Behaviour of Machine Tool Structures, (Russe, Bulgaria, 1993)

7. V. Năstăsescu, Metoda elementelor finite, (Editura Academiei Tehnicii Militare, Bucuresti, 1995)

8. I.-O. Popp, S.Cilinghir, Conferinta de dinamica masinilor, Contributii privind studiul comportarii dinamice a bazaltului, (1997)

9. I.-O. Popp, Contributii la cercetarea comportarii bazaltului supus unor solicitari specifice masinilor unelte (Phd tezis "Lucian Blaga" University of Sibiu, Romanian, 1999)

10. C. Girjob, G. Racz, MSE 2017, Study of the Formability of Laminated Lightweight Metallic Materials, (Sibiu, Romanian, 2017)

11. C. Biriș, G. Racz, IManEE 2017, Researches regarding the reducing of burr size by optimizing the cutting parameters on a CNC milling machine, (Pitești, Romanian, 2017)

12. G. P. Rusu, M. O. Popp, M. Oleksik, C. Rodean, IManEE 2017, Numerical simulation of material failure in single point incremental forming process, (Pitești, Romanian, 2017) 